\section{The Orthodontic National Group}

$\mathrm{T}$ he origins of the Orthodontic National Group (ONG) are found within the British Orthodontic Society (BOS) and the British Orthodontic Conference (BOC). In 1993 the organising committee of the BOC encouraged this group formation which would advise on future conference programmes for dental nurses. This would further inspire and encourage full team participation at impending conferences.

Membership of the ONG is around the 500 mark. Online membership application is available on the website and direct debit can be set up or card payments can be made. Membership is open to dental nurses and orthodontic therapists. More information is available on the ONG's website and Facebook page.

The ONG's mission statement is: 'The Orthodontic National Group is passionate about orthodontics, and provides a platform for education and valuable information to propel the work of orthodontic nurses and therapists throughout the UK'.

Services provided to members are:

- Two full study days at BOC and one spring study day annually

- Continuing professional development

- ProDental access and membership for online CPD

- Access to BOS VLE and Digitutor

- e-journals three times a year

- Discounted members' rates for BOC and other study days

- Access to BOS News and Clinical Effectiveness Bulletins

- Help and guidance as required for workplace support and advice on education

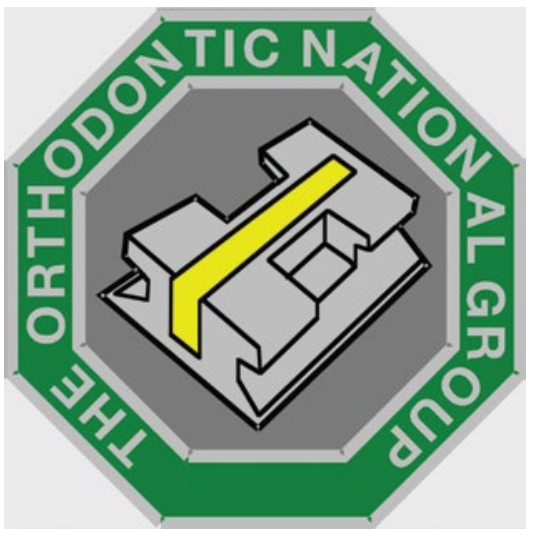

- Website with members only area

- Social media platforms.

The ONG's greatest achievements to date include:

- Working with the General Dental Council (GDC) to develop the Scope of practice

- Working with the BOS and the GDC to develop the new category of dental care professional (DCP) - the orthodontic therapist

- Working with the BOS to develop and update the supervision guidelines for the orthodontic therapist

- Achieving 25 years as a Group offering support and guidance to dental nurses and more recently to orthodontic therapists as well.

In the next few years, the ONG plans:

- To continue to provide study days and to introduce more hands-on and workshops when COVID allows!

- To provide webinars, possibly working with ProDental and BOS

- To increase membership

- To further develop the affiliation with BOS.

\title{
Ann completes 28 years on the Board of the Benevolent Fund
}

Ann Rockey has retired as Treasurer of the BDA Benevolent Fund after being on the Board since 1992. Ann (pictured) was Chairman for six years from 2011 and Treasurer since 2017. She has now been made a Vice President.

At the virtual AGM of the Benevolent Fund in September, Ann was presented with flowers and champagne (by her husband on behalf of the Board) in recognition of her support and time over the years.

In a thank you message sent afterwards Ann said: 'I want to thank you all most sincerely for your support, friendship, and wise counsel shown to me over quite a period of time. I would also like to thank you all for honouring me with the appointment to the Vice President post. I will be joining an elite group of past Trustees and I am most grateful, and will do my utmost to fulfil the responsibilities associated with the post.

'It will be and is quite a wrench to stand down after being involved with the Fund for 28 years; it has been a privilege to support our professional colleagues in times of need. Working with such great

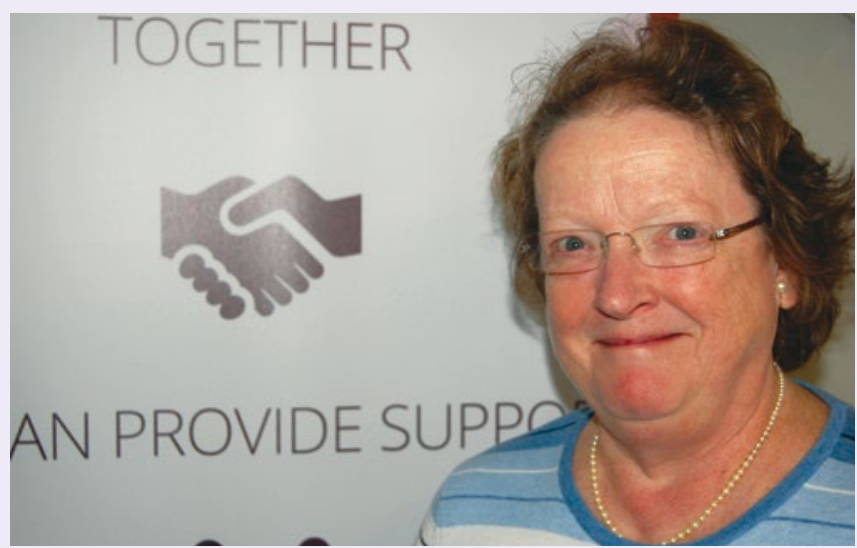

teams has been hard work, very rewarding and at times great fun.

'Kindest regards to you all and I wish you all ongoing success in your important, caring, and supportive work for our wonderful profession.' 